\title{
An Experimental Investigation of Accelerated Carbonation on Properties of Concrete
}

\author{
Shaik Hussain ${ }^{\mathrm{a}, *}$, Dipendu Bhunia ${ }^{\mathrm{b}}$, and Shamsher B. Singh ${ }^{\mathrm{c}}$ \\ Department of Civil Engineering, BITS Pilani, Jhunjunu, 333031, \\ E-mail: ahussain21dec@gmail.com (Corresponding author),bdipendubhunia@gmail.com, \\ csbsinghbits@gmail.com
}

\begin{abstract}
This study deals with the effect of carbonation on the mechanical properties such as compressive strength, flexural strength and durability like depth of carbonation and volume of permeable voids of the concrete cast using ordinary Portland cement over a time period of up to 1 year. To study the behavior of carbonation front of concrete in presence of varying water content, water binder ratios of $0.35,0.50$ and 0.65 are chosen. It is observed that the volume of permeable voids of concrete has decreased, with an increase in compressive strength, flexural strength, and depth of carbonation as the number of days of exposure of concrete specimen to high carbon dioxide increased.
\end{abstract}

Keywords: Compressive strength, depth of carbonation, flexural strength and volume of voids.

ENGINEERING JOURNAL Volume 20 Issue 2

Received 28 April 2015

Accepted 14 September 2015

Published 18 May 2016

Online at http://www.engj.org/

DOI:10.4186/ej.2016.20.2.29 


\section{Introduction}

The reason for the lack of durability of concrete may be determined if the microstructure of concrete and its response to aggressive environmental conditions are studied. Despite its adverse effects on reinforced structures, one cannot ignore the benefits of carbonation on enhancing the mechanical properties of unreinforced concrete. It is one of the long-term effects, which lead to decrease in the surface porosity. The green house gas $\mathrm{CO}_{2}$, released by most of the cement based industries; for certain extent is absorbed by the concrete structures contributing to the fight against changes in the climate due to green house effect. The study of this is relatively imperative when the amount of carbon dioxide emitted and the amount reabsorbed are in certain functional constitution [1].

Carbonation, which is one of the major causes for structure deterioration, is the reaction of the hydration products, which are dissolved in the pore water in concrete with the carbon dioxide in the air. When carbon dioxide $\left(\mathrm{CO}_{2}\right)$ from atmosphere comes in contact with the hydration products of cement, it changes the physical and chemical properties of the concrete [2-3]. It is process of formation of $\mathrm{CaCO}_{3}$ from $\mathrm{Ca}(\mathrm{OH})_{2}$ in the presence of carbon dioxide [4]. Carbon dioxide in atmosphere reacts with calcium content in cement and water in pores of concrete forming carbonic acid; which further forms $\mathrm{CaCO}_{3}$ upon reaction with hydroxides of calcium. To begin with, $\mathrm{CO}_{2}$ diffuses through the surface of the concrete through its interconnected capillary pores and dissolute as carbonic acid $\left(\mathrm{H}_{2} \mathrm{CO}_{3}\right)$. It is responsible for the formation of $\mathrm{HCO}_{3}$ and $\mathrm{CO}_{3}{ }^{2-}$ ions and the dissolution of hydration products of cement such as $\mathrm{Ca}(\mathrm{OH})_{2}$ to release $\mathrm{Ca}^{2+}$ and hydroxyl ions and the formation of $\mathrm{CaCO}_{3}$ [5]. The first reaction is in the pores of the concrete where carbon dioxide and water react to form carbonic acid. The carbonic acid then reacts with the calcium phases and forms calcium carbonate. Once the calcium hydroxide from the concrete is converted into calcium carbonate, the calcium silicate hydrates liberate calcium oxide, which further leads to calcium carbonate. The $\mathrm{pH}$ value of pore solution of concrete is around 12.6-13 [6], this is because of the dissolution of $\mathrm{Ca}(\mathrm{OH})_{2}$ which leads to the presence of hydroxyl ions in the pore water.

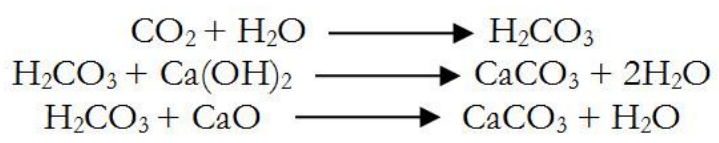

The factors that primarily influence the rate of carbonation are type and amount of pozzolanic material, the water binder ratio, the porosity of the material, the moisture in the surrounding and the duration of curing $[7,8]$. The diffusion of carbon dioxide $\left(\mathrm{CO}_{2}\right)$ within concrete porosity is one of the most common aggressive ingresses $[9,10]$.

To measure the amount of carbon dioxide absorbed per gram of cement, Galan et al. [1] used 15 types of cement to produce concrete mixes with water cement ratios of 0.45 and 0.60 and exposed them to various environmental conditions. The depth of carbonation and its rate of propagation along with carbon dioxide intake for both the water cement ratios have been determined. It was found that the samples exposed to open environment and sheltered from rain have had maximum depth of carbonation after 1 year, appearing colorless all over the area tested, compared to those unsheltered from rain which had a soft pink color indicating the fact that the $\mathrm{pH}$ has dropped, not below 8 unlike the previous case.

The diffusion of carbonation is lower in surface protected concrete than in non-protected one according to Jose and Cristela [11]. The authors [11] illustrate that the use of epoxy resin has shown a better protection compared to acrylic and siloxane. The carbonation diffusion coefficient increased with the water cement ratios, which is accountable due to the increase in porosity of concrete. Diffusion coefficient is the quantity of a substance that diffuses from one region to another passing through each unit of cross section per unit of time when the volume-concentration gradient is unity.

Yongsheng et al. [12] deduced that the effect of carbon dioxide concentration and the carbonation duration is very little on the length of the semi-carbonation zone where the value of $\mathrm{pH}$ is between 8.3 to 12.6. In their study, the authors [12] have deduced that for high strength concrete and for high relative humidity, the length of the semi-carbonation zone is shorter. The length of semi-carbonated zones under natural environmental conditions is more than that for high $\mathrm{CO}_{2}$ condition. The authors [12] have accounted this for the difference in temperature and relative humidity.

Neves et al. [13] studied the influence of age and environmental conditions on the ratio of accelerated and natural carbonation coefficients and concluded that only the environmental conditions have an influence on the ratio. Authors [13] have suggested that when $\mathrm{CO}_{2}$ concentrations differ slightly from $5 \%$ 
in accelerated carbonation resistance testing, a correction of the acceleration factor (slope of accelerated and natural carbonation coefficients) by the square root of accelerated carbon dioxide concentrations ratio is used.

Cheng, et al. [14] has conducted a study on the depth of carbonation for accelerated carbonated concrete and found that the $\mathrm{pH}$ values using phenolphthalein indicator are generally 9 and 7.5 for $50 \%$ and $100 \%$ degree of carbonation, respectively. The authors [14] have concluded that the semi-carbonated zone has carbonation degree between $0-50 \%(9<\mathrm{pH}<11.5)$ and fully carbonated has carbonation degree greater than $50 \%(\mathrm{pH}<9)$. If the direction of loading face and face exposed to carbonation is orthogonal; the enhancement in the compressive strength is significant. The enhancement in the mechanical properties of concrete does not prove it durable as once the carbonation reaches the rebar-concrete interface mechanical properties of concrete degrade [15].

Modern studies have showed that accelerated carbonation curing of concrete after a preconditioning has effectively replaced steam curing for precast concrete production [16]. The advantages of carbonation curing include improved dimensional stability, increased impermeability and strength, and enhanced chemical and efflorescence resistance with reduced time and energy demands for production. [17].

Concrete made with Portland cement shows a dissimilar behavior compared materials made with cement blended with mineral admixtures (e.g., blast furnace slag, fly ashes, or silica fumes) whose carbonation can cause a higher porosity, and thus a lowering of the durability [18].

\section{Materials and Methodology}

The study on the depth of carbonation at various stages of $\mathrm{CO}_{2}$ intake and $\mathrm{CaCO}_{3}$ conversion has been of acute interest. Hence in the present study, various water cement ratios are adopted to check the effect of carbonation on the properties of concrete such as compressive strength, flexural strength, volume of permeable voids and the depth of carbonation.

Ordinary Portland cement of 43 grade has been used for all mixes and the specific gravity was found as 3.15. The coarse aggregate used was crushed basalt with a specific gravity of 2.77 and fine aggregate with 2.42.The coarse aggregates were in a size range of 12.5 to $20 \mathrm{~mm}$ while fine aggregates were in a range of 0.075 to $4.75 \mathrm{~mm}$. This was consistent with respect to the specifications given in IS 2386 (Part 3) 1963 [19]. The particle size distribution curves for the fine aggregates and coarse aggregates are shown below in Figs. 1 and 2, respectively. Water reducing admixture has been used to attain a slump of $100 \pm 20 \mathrm{~mm}$. Its specific gravity was found to be 1.08. Table 1 shows the physical characteristics of the cement and Table 2 depict the chemical composition of the cement used in the design mixture of the concretes. The water binder ratios selected as $0.35,0.5$ and 0.65 pertain to a design mix selected suitably in accord to IS 10262 (2009) [20].

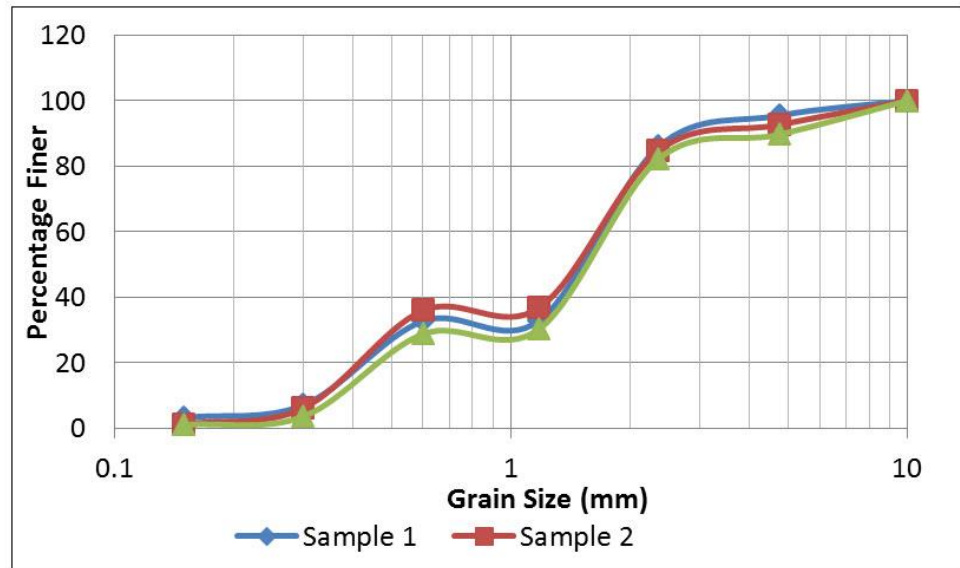

Fig. 1. Particle size distribution curve of fine aggregates. 


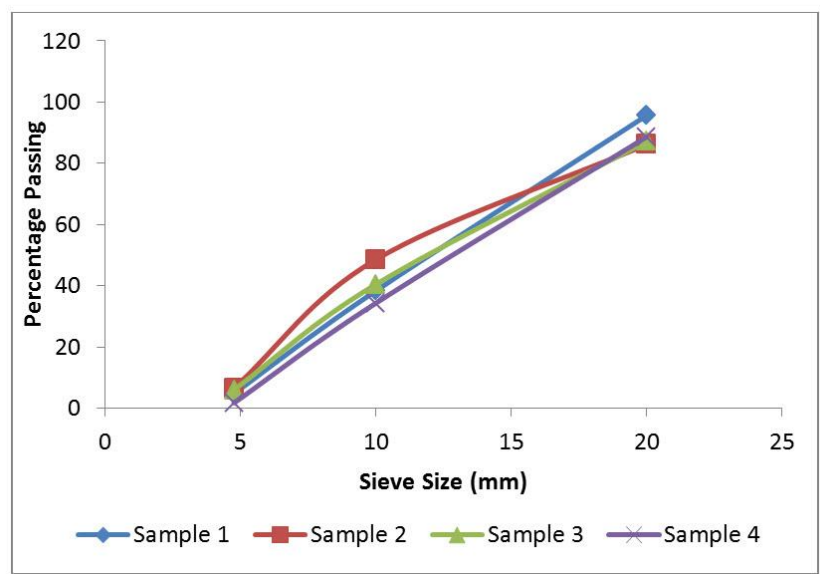

Fig. 2. Particle size distributions of coarse aggregates.

Table 1. Physical characteristics of cement.

\begin{tabular}{lc}
\hline Physical Characteristics & OPC 43 grade \\
\hline Density $\left(\mathrm{kg} / \mathrm{m}^{3}\right)$ & 3090.15 \\
Specific gravity & 3.15 \\
Fineness $(\%)$ & 8 \\
Water demand $(\%)$ & 33 \\
\hline
\end{tabular}

Table 2. Chemical composition of the cement.

\begin{tabular}{lc}
\hline Chemical composition & OPC 43 grade (\%) \\
\hline $\mathrm{SiO}_{2}$ & 20.27 \\
$\mathrm{Al}_{2} \mathrm{O}_{3}$ & 5.32 \\
$\mathrm{Fe}_{2} \mathrm{O}_{3}$ & 3.56 \\
$\mathrm{Al}_{2} \mathrm{O}_{3}+\mathrm{Fe}_{2} \mathrm{O}_{3}$ & 8.88 \\
$\mathrm{CaO}$ & 60.41 \\
$\mathrm{MgO}$ & 2.46 \\
$\mathrm{SO}_{3}$ & 3.17 \\
Loss on ignition & 3.55 \\
\hline
\end{tabular}

Table 3. Composition of concretes.

\begin{tabular}{ccccc}
\hline \multicolumn{5}{c}{ Mix proportions for 28 day strength of $\mathbf{3 0 - 3 5 ~} \mathbf{~ M P a ~ i n ~} \mathbf{~ k g} / \mathbf{m}^{\mathbf{3}}$} \\
\hline Water binder ratio & Cement & Water & Coarse Aggregate & Fine Aggregate \\
$\mathbf{0 . 3 5}$ & 450 & 157 & 1088 & 557 \\
$\mathbf{0 . 5 0}$ & 394 & 197 & 1125 & 655 \\
$\mathbf{0 . 6 5}$ & 304 & 197 & 1114 & 734 \\
\hline
\end{tabular}

Usual atmospheric concentrations of carbon dioxide are $0.03 \%$ by volume, but the samples in the accelerated carbonation chamber (ACC) are exposed to a carbon dioxide concentration of $5 \%$ to accelerate the process of carbonation and study its effects. The relative humidity is kept at $60-70 \%$ and the temperature of the chamber is maintained between $25^{\circ} \mathrm{C}$ to $35^{\circ} \mathrm{C}$. This $\mathrm{RH}$ was chosen because carbonation kinetics is known to be maximal between 50 and $70 \%$. However, this RH range was found to be optimal mainly for classical mixtures with Portland cement, i.e. ordinary concretes and mortars [21, 22]. Design mix proportions of the concrete for the water binder ratios of $0.35,0.50$ and 0.65 are given in Table 3 . Compressive strength of a concrete refers to the capacity of concrete to withstand loads in axial direction. The cubes of dimension $150 \times 150 \times 150 \mathrm{~mm}^{3}$ were cast with the nominal aggregate size not exceeding20 $\mathrm{mm}$ and exposed to high amounts of carbon dioxide in accelerated carbonation chamber. Compressive strength is measured by placing the cubes in the machine in such a way that the load is applied to opposite sides of the cubes as cast and by dividing the maximum load applied to the specimen during the test by cross sectional area. The opposite casting faces of the cube are the only faces that are not painted as shown in Fig. 3 (a). This enables uni-directional ingress of carbon dioxide into the cube. 


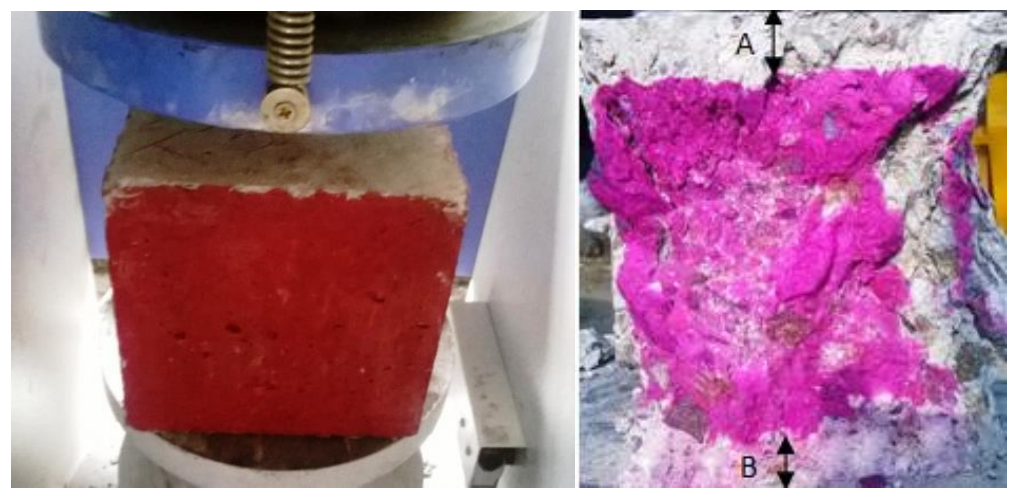

Fig. 3. (a) Compressive strength of concrete; (b) Measure of depth of carbonation.

Modulus of rupture, which is the measure of flexural strength of concrete, is measured for the various water binder ratios for their respective exposure duration to accelerated carbonation. Prisms of size150X $150 \times 700 \mathrm{~mm}$ were cast and kept in carbonating chamber for curing and then removed and tested after the predetermined duration of exposure. Modulus of rupture $\mathrm{f}_{\mathrm{b}}$ is calculated using the following formulae.

$$
\begin{gathered}
f_{b}=\frac{(p \times l)}{b \times d^{2}} \\
f_{b}=\frac{(3 p \times a)}{b \times d^{2}}
\end{gathered}
$$

Equation (1) is used when ' $a$ ' is greater than $200 \mathrm{~mm}$ for $150 \mathrm{~mm}$ specimen, or greater than $133 \mathrm{~mm}$ for a100 mm specimen and Eq. (2) is used when 'a' is less than $200 \mathrm{~mm}$ but greater than $170 \mathrm{~mm}$ for $150 \mathrm{~mm}$ specimen or less than $133 \mathrm{~mm}$ but greater than $110 \mathrm{~mm}$ for a100 $\mathrm{mm}$ specimen, where 'a' equals the distance between the line of fracture and nearest support, measured on the centerline of the tensile side of the specimen in $\mathrm{cm}$ shown in Fig. 4 as per IS $516-1959$ [23].

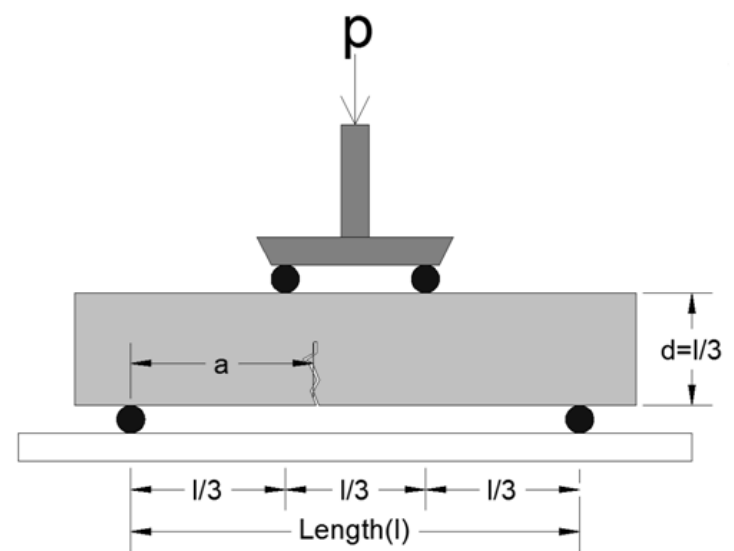

Fig. 4. Flexural Strength test of concrete specimen.

The depth of carbonation is measured with the phenolphthalein indicator. Phenolphthalein is a colorless acid indicator, which turns red when the $\mathrm{pH}$ is above 9.5 i.e., when the concrete is alkaline. This drop in the $\mathrm{pH}$ is due to the formation of $\mathrm{CaCO}_{3}$ from $\mathrm{Ca}(\mathrm{OH})_{2}$. The depth of carbonation is measured by taking the average of the two values obtained from both the non-painted faces of the concrete cube as shown in Fig. 3(b).

Volume of permeable voids of the concrete is the volumetric proportion of the voids in concrete. The mechanical properties of the concrete are greatly influenced by its porosity and it is determined as per specifications of ASTM C 642-06 [24]. The concrete specimens once removed from carbonation chamber are kept in oven for 24 hours and weighed. This process is repeated until the difference between two successive readings is within $0.5 \%$ of the lesser weight. The specimens are then immersed in water for 48 hours and weighed after its surface is dried. The readings are taken till the difference between the readings is less than $0.5 \%$. After this the specimens are subjected to rigorous boiling for 5 hours and then weighed after 14 hours. Finally the specimens are suspended in water and their apparent weights are taken. The calculation of volume of permeable voids (\%) is done by the formulae mentioned in ASTM C 642-06 [24]. 


\section{Results and Discussions}

The following sections present the experimental results on compressive strength, flexural strength, and volume of permeable voids and depth of carbonation.

\subsection{Volume of Permeable voids (\%)}

As shown in Fig. 5, the volume of permeable voids of concrete specimens exposed to accelerated carbonation has decreased with an increase in the number of days of exposure. This might be accountable to the fact that the molecules of $\mathrm{Ca}(\mathrm{CO})_{3}$ occupy more volume compared to $\mathrm{Ca}(\mathrm{OH})_{2}$. On the contrary, calcium carbonate formed has low solubility and it therefore underwrites for the blocking of pores decreasing the permeability of the concrete. These observations signify that the carbonation decreases the surface porosity of the concrete, i.e., the zone where partial or full carbonation has transpired, because of which the decrease in the percentage of porosity with respect to exposure duration is steep at the beginning and moderate at the later stage. Figure 5 below shows the comparison of volume of permeable voids in accordance with curing conditions and water binder ratios. It is observed that the decrease is highest for the mix with water binder ratio of 0.35 , while there is no significant difference in the volume of permeable voids of mix with water binder ratios of 0.50 and 0.65 .

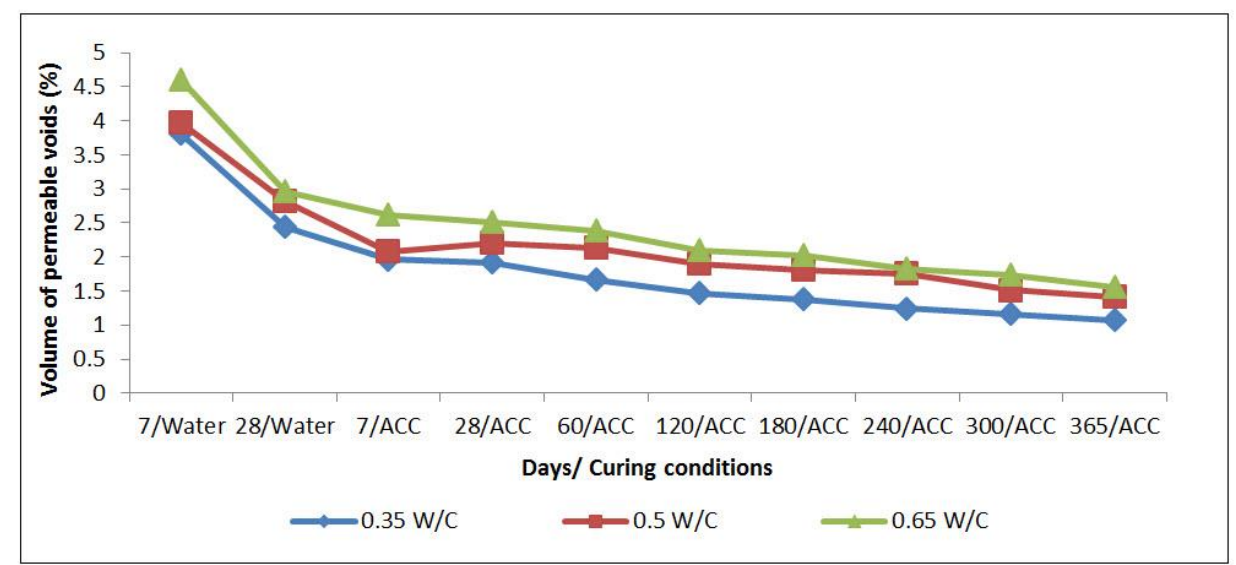

Fig. 5. Variation of volume of permeable voids of accelerated carbonated concrete with time.

\subsection{Compressive Strength}

As the duration of the exposure of the samples in the carbonation chamber increased as shown in Fig. 6, the compressive strength increased owing to the decrease in porosity and adjustment in the packing of molecules due to formation of the $\mathrm{CaCO}_{3}$ where the volume has been increased. This improves the strength of the samples further increasing the mechanical properties of the concrete. The compressive strength of the specimen decreased as the water binder increased. The reason may be resolved for the increment in the moisture content and the more pore water in the molecules of concrete. Though the surface of concrete specimen became less permeable, the non-carbonated zone has none of its porosity affected. And because of this assertion, the mechanical properties of the non-carbonated concert remain unaffected and thereby decrease in the compressive strength. Figure 6 shows the comparison of compressive strength in accordance with curing conditions and water cement ratios. 


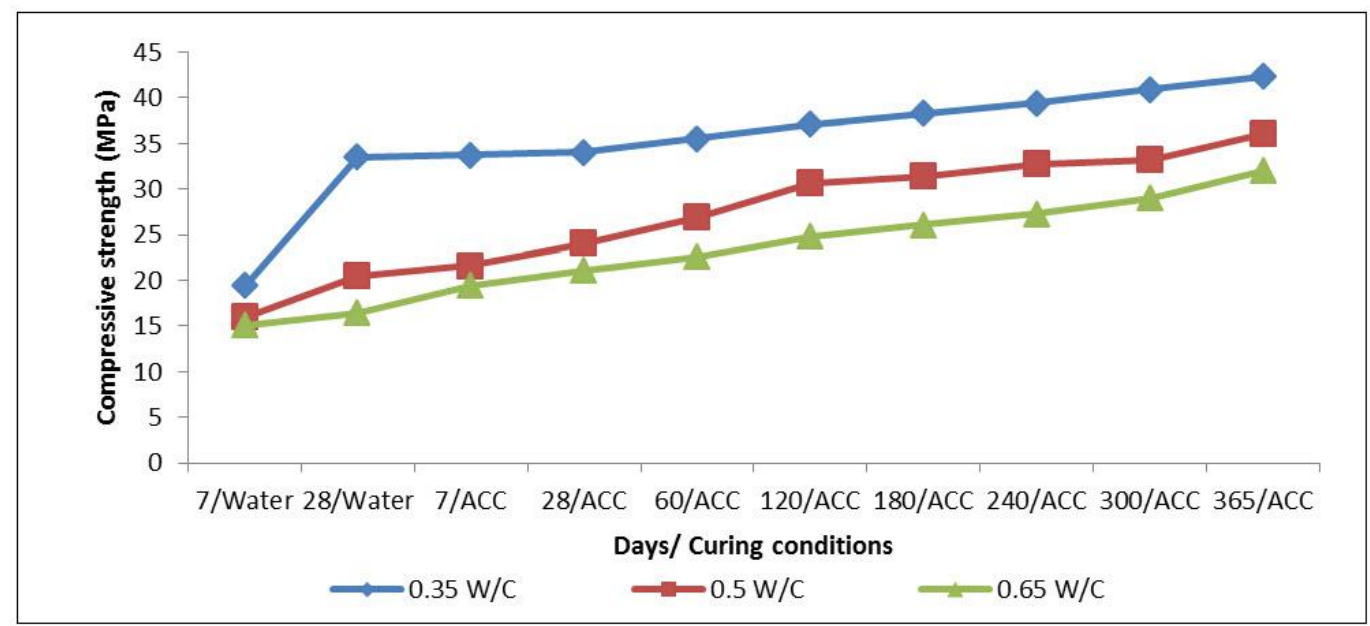

Fig. 6. Variation of compressive strength of accelerated carbonated concrete with time.

\subsection{Flexural Strength}

As shown in Fig. 7, the flexural strength increases with the duration of the exposure. The formation of calcium carbonate has improved the flexural behavior of the carbonated concrete acting as a thick protective layer of decreased porosity on the concrete surface.

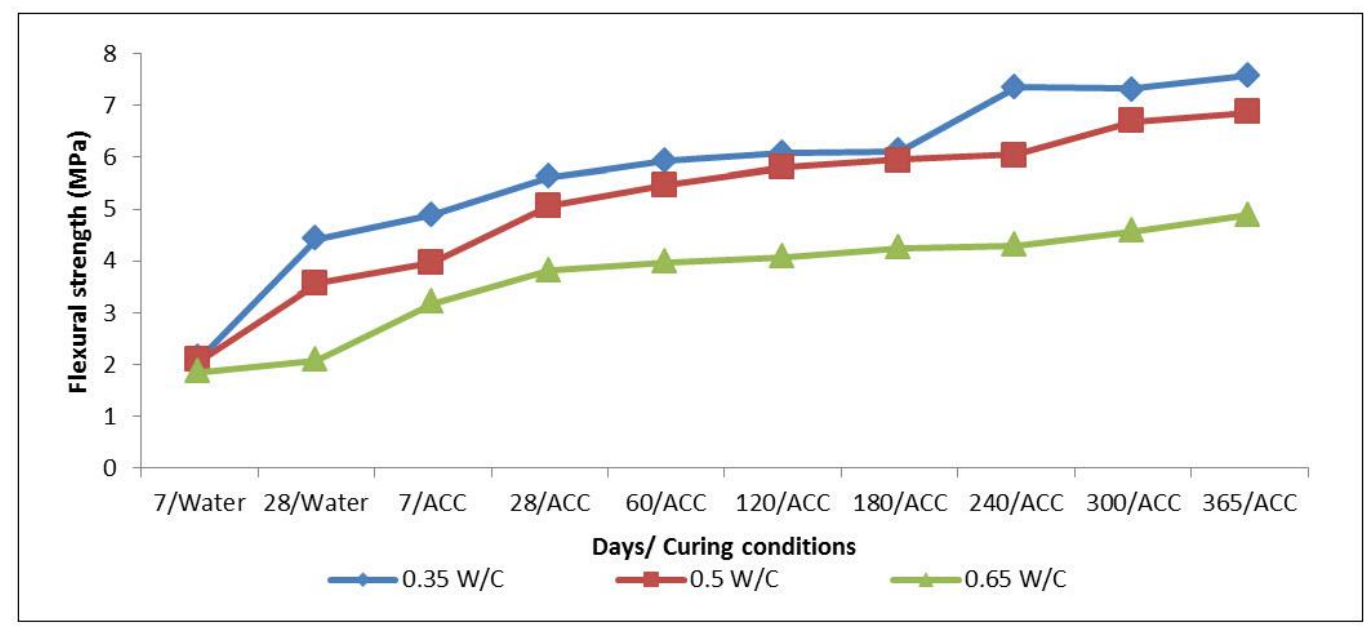

Fig. 7. Variation of flexural strength of accelerated carbonated concrete with time.

\subsection{Depth of Carbonation}

Figure 8 shows the comparison of depth of carbonation in accordance with curing conditions and water cement ratios. It is seen that the depth of carbonation increases with the increase in the carbonation duration and the water binder ratios. This may be attributed to the amount of diffused carbon dioxide present in the interconnected capillary pores of concrete. Lower water binder ratios lead to the densification of the pores. The moisture content in the concrete plays a predominant role in the amount of the carbon dioxide ingress in carbonation front. The faces of cube, which are not painted, are the ones, which are tested for the depth of carbonation. The depth of carbonation is taken as the average of the values obtained from both sides of the cube face. 


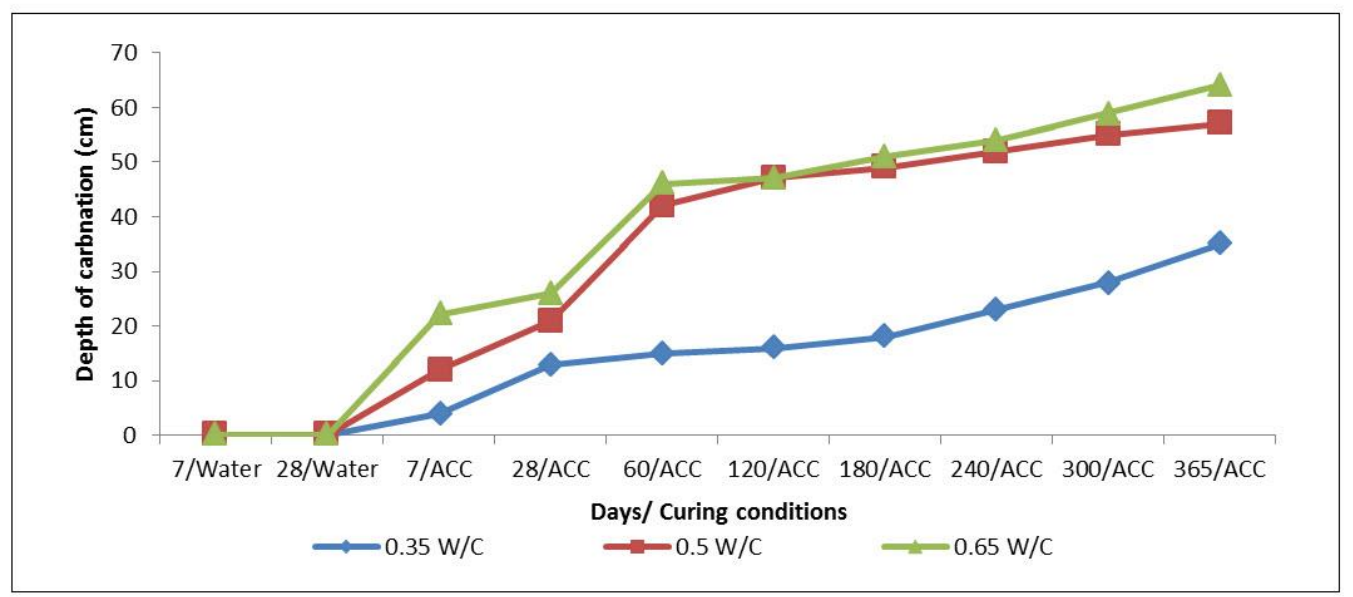

Fig. 8. Variation of depth of carbonation of accelerated carbonated concrete with time.

\subsection{Relation between Depth of Carbonation and Compressive Strength}

To formulate a relation between depth of carbonation and the compressive strength of concrete measured after being exposed to high amounts of carbon dioxide, the values of depth of carbonation and compressive strength obtained from the present research as well as those available in literature have been taken and represented graphically (Fig. 9). Roy et al. [25] have studied the durability of concrete by accelerated carbonation for a period of $1,4,8$ and 16 weeks with a carbon dioxide concentration of $6 \%$. In a research done by Khunthongkeaw, et al. [26], the depth of carbonation under natural and accelerated conditions of carbon dioxide concentrations has been compared and a relation has been formulated based on the carbon dioxide concentration, relative humidity and time of exposure. Cengiz [27] in his research emphasized on the influence of fly ash on accelerated carbonation of concrete and deduced that $50 \%$ replacement of fly ash has shown lesser carbonation compared to $70 \%$ replacement and normal Portland Cement Concrete. The values of depth of carbonation and compressive strength obtained from the above mentioned works have been taken and represented in a graph along with the work done in the present research. Equation (3) represents the empirical relation between compressive strength and depth of carbonation deduced from Fig. 9 .

$$
d=\frac{w C}{S}(43.11 \sqrt{t}-86.87)
$$

where $d$ is depth of carbonation (mm), $S$ is compressive strength (MPa), $w$ is water binder ratio, $C$ is concentration of carbon dioxide (percentage by volume) and $t$ is number days of concrete exposure to accelerated carbonation. Y-axis is fixed in accordance to the proportionality relation with depth of carbonation.

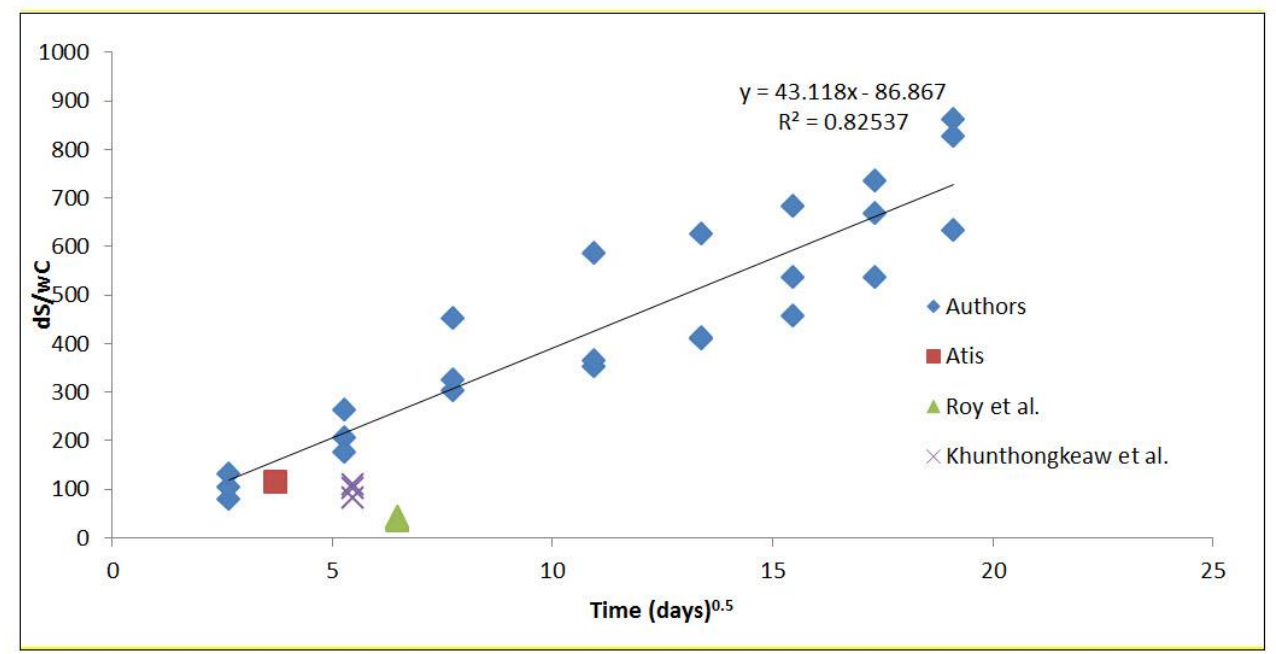

Fig. 9. Variation of depth of carbonation with time for a specified concrete. 


\section{Conclusions}

In this study various physical and mechanical properties of concrete exposed to accelerated carbonation have been investigated. Moreover, an empirical equation for predicting the depth of carbonation for a concrete mix has been presented. Within the scope of the present study, the following concluding remarks could be made.

i. The porosity of concrete decreases with increase in the carbonation duration. It makes the concrete less permeable and provides surface hardening.

ii. Due to the decrease in the porosity, the mechanical properties of the concrete such as its strength in compression and flexure have greatly improved. But as the water binder ratio increased, the advances in these properties have diminished. A steady increase in the mechanical properties has been seen on the samples subjected to accelerated carbonation for up to 1 year.

iii. The depth of carbonation has had a steep increase with the duration of exposure, i.e., as the exposure duration increased, the depth of carbonation has increased. Higher water binder ratios have shown high depths of carbonation. After 60 days of accelerated carbonation, the depth of completely carbonated zone has steadily increased unlike the steep rise for 60 days.

\section{Acknowledgements}

Department of Science \& Technology (SERB), New Delhi, supported the research presented in this paper. Any opinions, findings, and conclusions or recommendations expressed in this paper are those of the authors and do not necessarily reflect the views of the sponsors.

\section{References}

[1] I. Galan, C. Andrade, P. Mora, M. A. Sanjuan, J. C. Lopez-Agtti, and M. Prieto, "CO 2 sink effect of concrete carbonation," in Proceedings of Special Technical Sessions. Second International Conference on Sustainable Construction Materials and Technologies, Ancona, Italia, 2010.

[2] M. Castellot, C. Andrade, X. Turrillas, J. Campo, and G. J. Cuello, "Accelerated carbonation of cement pastes in situ monitored by neutron diffraction," Cem Conc Res, vol. 38, pp. 1365-1373, 2008.

[3] M. F. Bertos, S. J. R. Simons, C. D. Hills, and P. J. Carey, "A review of accelerated carbonation technology in the treatment of cement-based materials and sequestration of $\mathrm{CO}_{2}$, " J Hazard Mater, vol. B112, pp. 193-205., 2004.

[4] J. M. Chi, R. Huang, and C. C. Yang, "Effects of carbonation on mechanical properties and durability of concrete using accelerated testing method," Journal of Marine Science and Technology, vol. 10, no. 1, pp. 14-20, 2002.

[5] M. Thiery, G. Villian, P. Dangla, and G. Platret, "Investigation of the carbonation front shape on cementitious materials: Effects of the chemical kinetics," Cem Conc Res, vol. 37, pp. 1047-1058, 2007.

[6] K. Simsomphon and L. Franke, "Carbonation rates of concretes containing high volume of pozzolanic materials,” Cem Conc Res, vol. 37, pp. 1647-1653, 2007.

[7] H. Roper and D. Baweja, "Carbonation-chloride interactions and their influence on corrosion rates of steel in concrete," Durability of Concrete, ACI SP-126, pp. 295-315, 1991,.

[8] L. V'eleva, P. Castro, G. Hernandez, and M. Schorr, "The corrosion performance of steel and reinforced concrete in a tropical humid climate. A review," Corros Rev., vol. 16, no. 3, pp. 235-284, 1998.

[9] O. Omikrine and A. Mokhtar, "A proposed methodology for quantitative investigation of carbonation in polymer modified mortars," Exp. Tech., vol. 33, pp. 59-65., 2009.

[10] O. Omikrine, A. Mokhtar, P. Turcry, and B. Ruot, "Consequences of carbonation on microstructure and drying shrinkage of a mortar with cellulose ether," Construction and Building Materials, vol. 34, pp. 218-225, 2012.

[11] J. B. Aguiar and C. Júnior, "Carbonation of surface protected concrete," Construction and Building Materials, vol. 49, pp. 478-483., 2013. 
[12] Y. Yuan, J. Shen, Y. Ma, and S. Lai, "Comparison of concrete process under natural condition and high $\mathrm{CO}_{2}$ concentration environments," Journal of Wuban University of Technology, vol. 25, no. 3, pp. 515521, June 2010.

[13] R. Neves, F. Branco, and J. de Brito, "Field assessment of the relationship between natural and accelerate concrete carbonation resistance," Cement and Concrete Composites, vol. 41, pp. 9-15, 2013.

[14] C. F. Chang and J. W. Chen, "The experimental investigation of concrete carbonation depth," Cement and Concrete Research, vol. 36, pp. 1760-1767. 2006.

[15] J. J. Chang, W. Yeih, R. Huang, and J. M. Chi, "Mechanical properties of carbonated concrete," Journal of the Chinese Institute of Engineers, vol. 26, no. 4, pp. 513-522., 2003.

[16] V. Rostami, Y. Shao, and A. Boyd, "Carbonation curing versus steam curing for precast concrete production," Journal of Materials in Civil Engineering, vol. 24, no. 9, pp. 1221-1229, 2012.

[17] P. Soroushian and J. Hsu, "Advanced curing of current-based materials," U.S. Patent No. 5,935,317 1999.

[18] L. Ceuklaire and D. Nieuwenburg, "Accelerated carbonation of a blast furnace cement concrete," Cement and Concrete Research, vol. 23, pp. 442-452, 1993.

[19] Methods of Test for Aggregates for Concrete, Specific Gravity, Density, Voids, Absorption and Bulking, IS 2386 (Part III), New Delhi, India 1997.

[20] Concrete Mix Proportioning-Guidelines, IS 10262, New Delhi, India, 2009.

[21] G. Verbeck, "Carbonation of hydrated Portland cement," ASTM Spec. Tech. Publ., vol. 205, pp. 17-36, 1958.

[22] M. Thiery, "Modélisation de la carbonatation atmosphérique des matériaux cimentaires. Prise en compte des effets cinétiques et des modifications microstructurelles et hydriques," Ph.D. thesis, LCPC, Paris, 2005.

[23] Methods of Tests for Strength of Concrete, IS 516, New Delhi, India 1959.

[24] Standard Test Method for Density, Absorption, and Voids in Hardened Concrete, ASTM C 642-06, Philadelphia, USA, 2006.

[25] S. K. Roy and K. B. Poh, and D. O. Northwood, "Durability of concrete-accelerated carbonation and weathering studies," Building and Environment, vol. 34, pp. 597-606, 1999.

[26] J. Khungthongkeaw, S. Tangtermsirikul, and T. Leelawat, "A study on carbonation depth prediction for flyash concrete," Construction and Building Materials, vol. 20, pp. 744-753, 2006.

[27] D. A. Cengiz, "Accelerated carbonation and testing of concrete made with flyash," Construction and Building Materials, vol. 17, pp. 147-152, 2003. 